\title{
The Challenges of Outcomes-Based Contract Implementation for Medicines in Europe
}

\author{
Natalie Bohm ${ }^{1} \cdot$ Sarah Bermingham ${ }^{2}$. Frank Grimsey Jones ${ }^{2}$ [D . Daniela C. Gonçalves-Bradley ${ }^{2} \cdot$ \\ Alex Diamantopoulos ${ }^{2} \cdot$ Jessica R. Burton ${ }^{1} \cdot$ Hamish Laing $^{3}$
}

Accepted: 18 July 2021 / Published online: 4 September 2021

(c) The Author(s) 2021

\begin{abstract}
Objectives The aim was to outline the challenges of implementing outcomes-based contracts (OBCs) in Europe.

Methods A scoping review was conducted, building on the searches of a previous systematic review and updating them for December 2017 until May 2021. The combined results were screened, based on inclusion and exclusion criteria. All identified studies published in the English language that described specific OBC schemes for medicines in European countries were included. Insights into the challenges of OBCs were extracted and analysed to develop a conceptual framework.

Results Ten articles from the previous systematic review matched our inclusion criteria, along with 14 articles from electronic searches. Analysis of these 24 articles and classification of the challenges revealed that there are multiple barriers that must be overcome if OBCs that benefit all stakeholders are going to be adopted widely across Europe. These challenges were grouped according to five key themes: negotiation framework; outcomes; data; administration and implementation; and laws and regulation.

Conclusions If the promise of OBCs is to be fully realised in Europe, there remain major challenges that need to be overcome by all stakeholders working in partnership. The overlapping and interconnected nature of these challenges highlights the complexity of $\mathrm{OBC}$ arrangements.
\end{abstract}

Natalie Bohm

Natalie.Bohm@pfizer.com

1 Pfizer Limited, Walton Oaks, Dorking Road, Tadworth KT20 7NS, UK

2 Symmetron Limited, London, UK

3 Value-Based Health and Care Academy, School of Management, Swansea University, Swansea, UK

\section{Key Points for Decision Makers}

An analysis of the literature and classification of the challenges concludes there are multiple barriers that must be addressed if outcomes-based contracts (OBCs) that benefit all stakeholders are going to be adopted widely across Europe. These challenges can be grouped according to five key themes: negotiation framework; outcomes; data; administration and implementation; and laws and regulation.

The overlapping and interconnected nature of these challenges highlights the complexity of OBC arrangements. Acknowledging this complexity is the first step to moving forward; parties need to develop a fundamentally different approach to problem solving to progress from there. 


\section{Introduction}

The development of personalised therapies for increasingly smaller subsets of patients and potentially curative interventions for genetic diseases has provided a challenge to healthcare systems and the pharmaceutical industry. Smaller populations can result in insufficient evidence for formal reimbursement decisions as well as challenging threshold limitations, with tension in achieving access to innovative therapies that is both sustainable and incentivises innovation. In Europe, this tension is being considered through different mechanisms, including new licensing and access pathways. There is concern that this may introduce methodological complexity into health technology assessments (HTAs) [1]. This has renewed the focus on how best to pursue a value-based healthcare approach, with the aim of providing the best possible outcomes that matter to patients at the same or reduced cost.

As part of this approach, the pharmaceutical industry and payers have considered contracting agreements designed to achieve value for patients by linking reimbursement to outcomes achieved (including clinical outcomes and/or patient-reported outcomes [PROs]). Outcomes-based contracts (OBCs) have the potential to offer an opportunity to pursue a more effective allocation of resources, maximise patient health outcomes, promote the use of medicines best fit for patients, and incentivise the generation of additional evidence [2, 3]. However, uptake across Europe has been mixed, with higher uptake in Italy and Spain [4, 5], but a trend to simple discounting in the UK and elsewhere [6]. This may provide short-term relief to resource-constrained systems, but does not lead to a sustainable innovative ecosystem.

This review was performed to assess the challenges of developing OBCs in Europe with a view to understanding their complexity and barriers to implementation. This is the first review specifically focused on the challenges associated with implementing OBCs across European health systems, therapeutic areas and stakeholders, and addresses the question, 'What are the common challenges in implementing OBCs experienced by European health stakeholders?'

\section{Methods}

A scoping review based on Arksey and O'Malley's (2005) framework [7] was used to address the research question. This approach gives an overview of an area of research that is heterogeneous and rapidly evolving. It involves identifying the research question, identifying and selecting studies, then extracting and analysing the data, and reporting results.
Relevant studies were identified through a literature search. The search terms were based on a research paper by Cole et al. [8], which was produced in partnership with leading European health institutions and includes interviews, patient surveys and case studies, as well as multiple systematic literature reviews (SLRs). It included a systematic search of studies that reference specific OBC examples, but it did not fully consider challenges in implementation, looked at a broader scope of countries, and has not been updated since 2018. As this review aimed to appraise OBC implementation challenges, which are highly contextual, the narrower scope of European countries was used. The original search by Cole et al. ran between January 2007 and January 2018 (the search terms are presented in the electronic supplementary material). The search was updated for the current paper to May 2021. The updated searches were run in PubMed, Cumulative Index of Nursing and Allied Health Literature (CINAHL), Web of Science and EconLit, as was the case in Cole et al. [8]. The reference lists of SLRs eligible for inclusion were checked, and the search was extended by discussion with co-authors to identify any publications not published in peer-reviewed scientific papers. It became clear that saturation had been reached as no new subthemes were identified. After screening of titles and abstracts, full texts were reviewed independently according to the inclusion and exclusion criteria by two experienced reviewers. Data were extracted by independent reviewers using Microsoft Word and analysed using thematic analysis. Following familiarisation with the literature, passages of text describing specific challenges were extracted from included articles. These were coded in Microsoft Word, so that conceptual patterns could be identified. These were discussed and iterated by the reviewers to form higher order themes and subthemes, based on weight from the literature and consensus by the reviewers. This resulted in an inductively developed conceptual framework with a two-level hierarchy of broad themes and detailed subthemes. Following review of the included papers, the co-authors assessed the conceptual framework for clarity, comprehensiveness and credibility based on their experience. The framework was refined by integrating the interpretations of all authors until it was concluded that the data were fully contextualised.

\section{Results}

Database searches identified 390 records. Of those, 24 were shortlisted for full-text assessment, of which 12 met the inclusion criteria. From Cole et al. [8], ten studies met the inclusion criteria, and two additional studies were identified from the SLRs eligible for inclusion (Fig. 1). The main reason for exclusion was being a theoretical record, without reference to European OBCs $(N=11)$. 
Fig. 1 Inclusion and exclusion criteria for the literature search. $O B C s$ outcomes-based contracts

\begin{tabular}{|c|c|}
\hline Inclusion criteria & Exclusion criteria \\
\hline $\begin{array}{l}\text { - Specific OBC schemes for medicines, if } \\
\text { they include: } \\
\text { O Information on outcomes used in } \\
\text { the scheme } \\
\text { O Information on how these } \\
\text { outcomes are measured } \\
\text { - Papers in English } \\
\text { - Systematic reviews/Rapid Evidence } \\
\text { - Assessments as well as original research } \\
\text { Timeframe: } \\
\text { O Papers published between } \\
\text { January 2007 and January } 2018 \\
\text { (Cole 2019) } \\
\text { O Papers published between } \\
\text { December } 2017 \text { and May } 2021 \\
\text { (update) }\end{array}$ & $\begin{array}{l}\text { - Specific OBC schemes with no } \\
\text { information on outcome used } \\
\text { - Purely theoretical papers, only discussing } \\
\text { the methodology of OBC schemes } \\
\text { - OBC schemes for health care services, } \\
\text { systems, diagnostics, etc. (i.e. those that } \\
\text { are not specific to medicines) } \\
\text { - Commentaries, editorials and features } \\
\text { - Papers published before January } 2007 \\
\text { Papers that only include examples of } \\
\text { OBC schemes outside of European } \\
\text { countries (additional requirement). }\end{array}$ \\
\hline
\end{tabular}

The final sample included 24 studies (Table 1). Some studies were evaluations of a specific OBC case study, whilst others included a broader approach, with multiple OBC examples analysed in the same paper.

The key themes that were identified when analysing the 24 records were as follows: negotiation framework; outcomes; data; administration and implementation; and laws and regulation. Each of these themes was further detailed into sub-themes (Table 2). Sample quotes are provided that incapsulate the essence of each subtheme and illustrate the way in which passages of text were used to identify the theme.

Example OBCs are referenced in the following sections and summarised in Table 3.

\subsection{Negotiation Framework}

\subsubsection{Terminology}

There is variation in the terminology and taxonomy used for OBCs. They may also be called outcomes-based agreements, pay-for-performance agreements, risk-sharing agreements, cost-sharing agreements, coverage with evidence development (CED), access with evidence development, patient access schemes, conditional licensing, managed entry schemes, performance-based risk-sharing agreements and payment-by-result arrangements [2, 4, 5, 9-13]. Effective communication is the foundation of effective negotiation, and thus differences in terminology may be a barrier to a positive outcome.

\subsubsection{Trust}

An underlying lack of trust can undermine the establishment and implementation of OBCs $[14,15]$. Whilst there are examples of collaborations and partnerships working between industry and payers with respect to OBCs [11], for instance, the programme for bortezomib in multiple myeloma established between Johnson \& Johnson and the National Health Service (NHS) (UK), these are not the norm. Payers often suspect these schemes are extensions of marketing activities [16]. Payers also have concerns the Marketing Authorisation Holders (MAH) will overprice medicines with limited data at market entry, anticipating reduced revenues as the evidence base grows [10]. Likewise, payers expressed concerns that temporary coverages can become permanent [11], as reversing coverage decisions is a complex process [17].

OBCs require payers to trust that any refunds will be received. This process can be administratively complex and relies on the participation of stakeholders who are not incentivised to correctly implement the process $[10,18]$. An alternative refund model proposed in the literature is the use of bonus payments for the MAH, also known as success fee, when outcomes are achieved [18]. The main feature of this model is that payment is provided to the MAH after efficacy has been evaluated, which precludes costs for non-responders.

Loss aversion amongst patients complicates negotiations. Patients can be resistant to losing access to medicines, even if new evidence emerges that they are not cost-effective. Some OBCs are structured such that a medicine is reimbursed temporarily, whilst additional real-world evidence is collected [19]. For these agreements to be effective, payers need to be confident that they can withdraw a medicine when it is not found to be cost-effective, without mass resistance from patients [11]. If this is not the case, a payer may prefer to delay market access, until further evidence is gathered upfront [19]. 


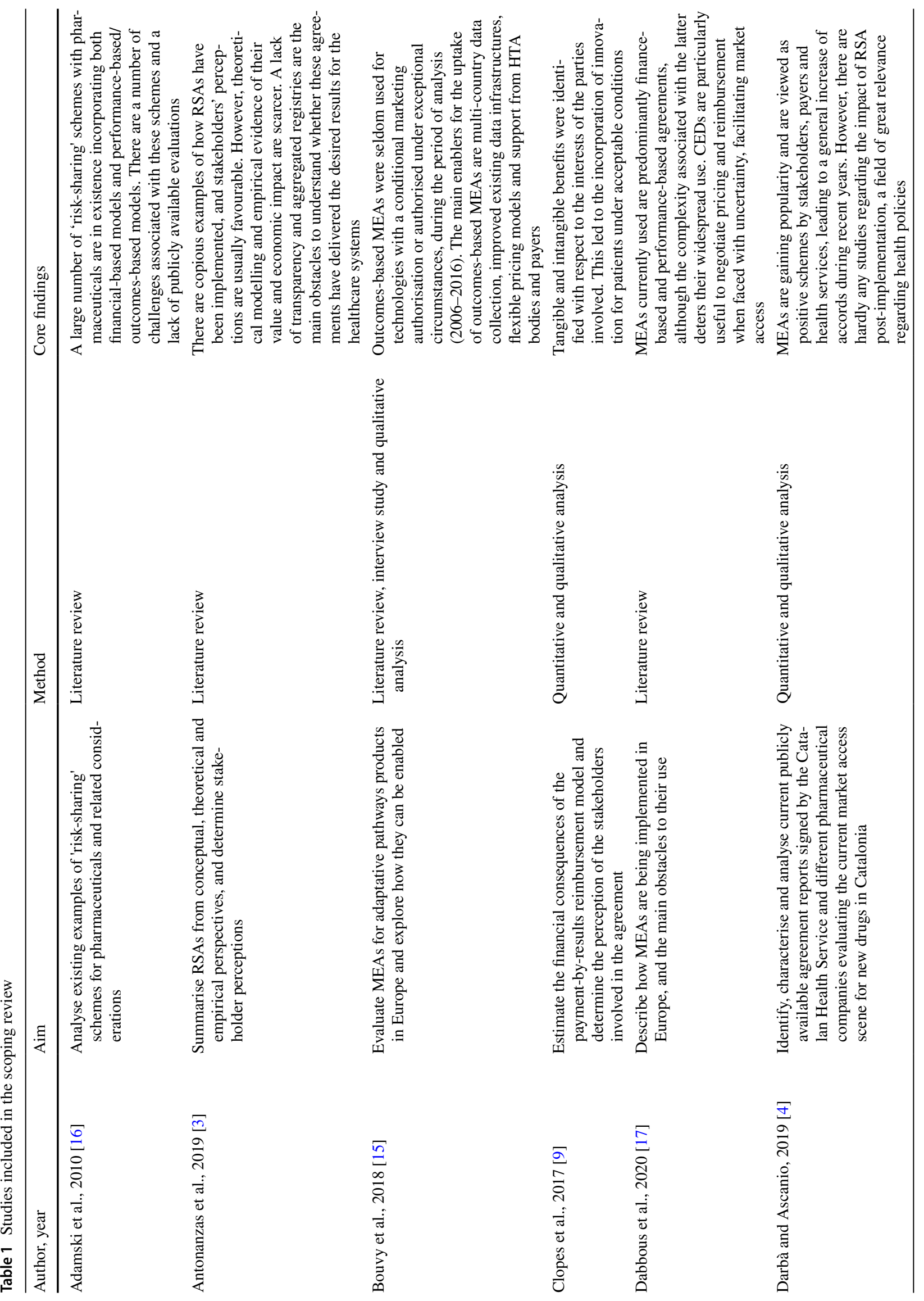




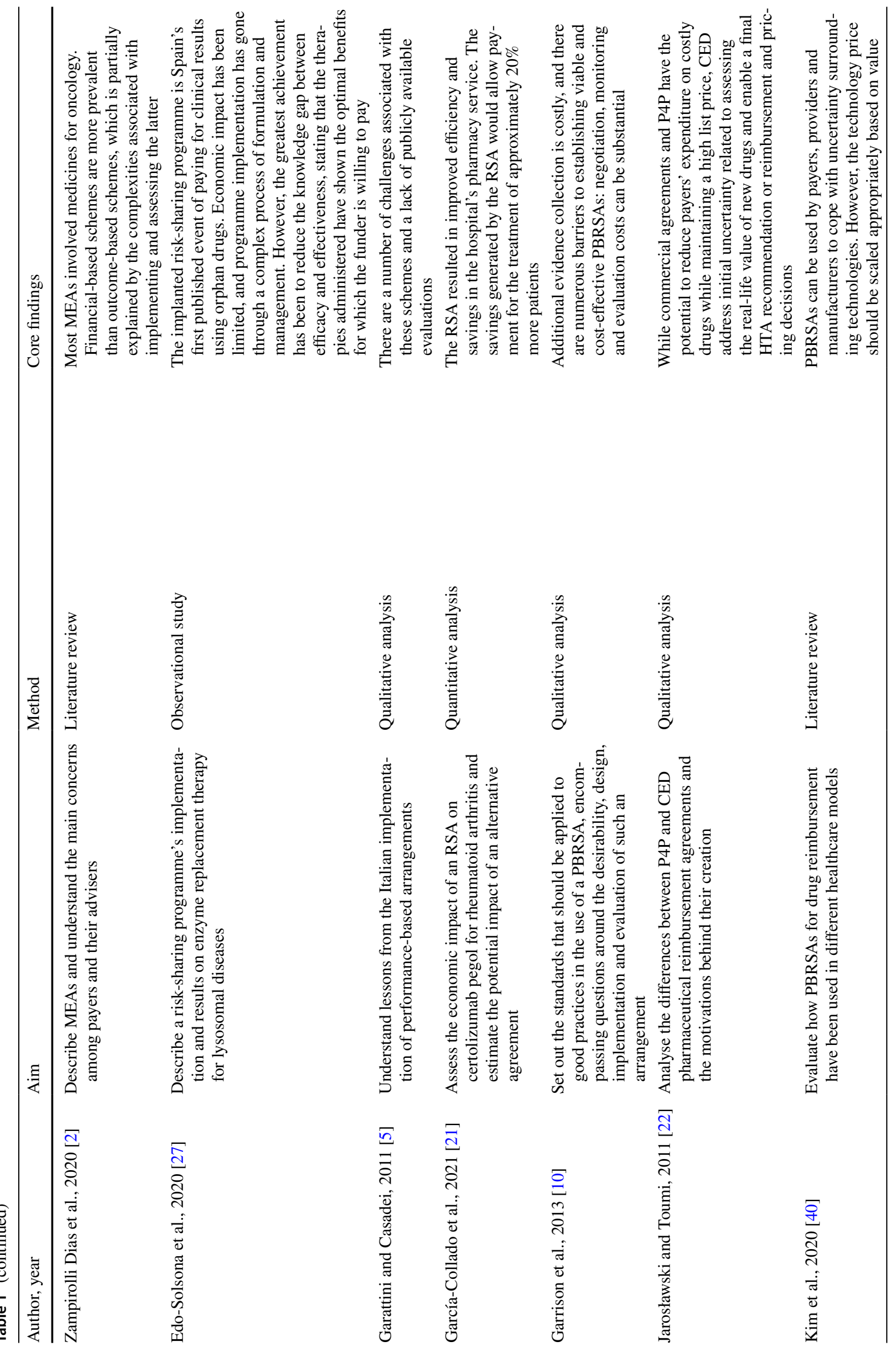




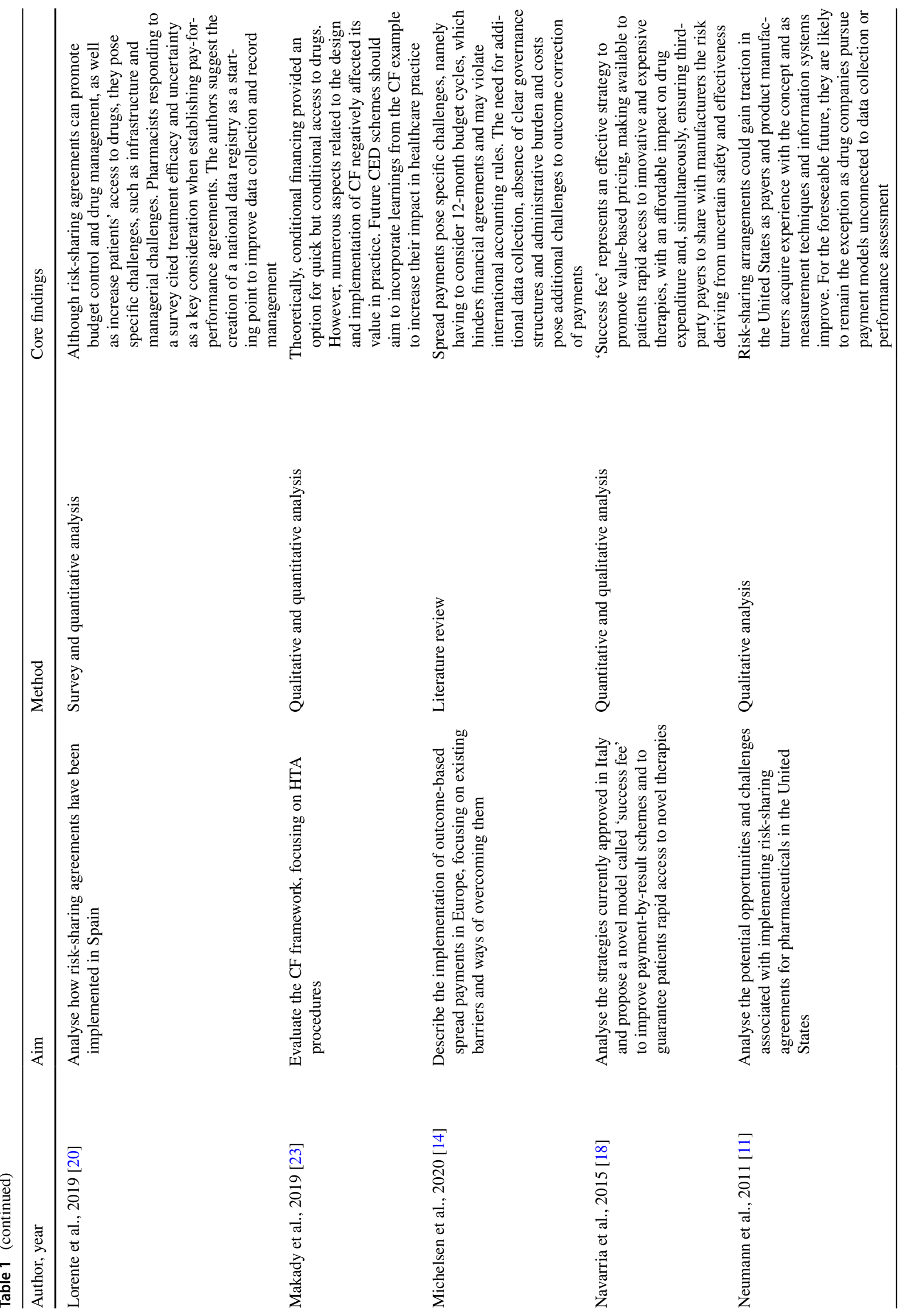




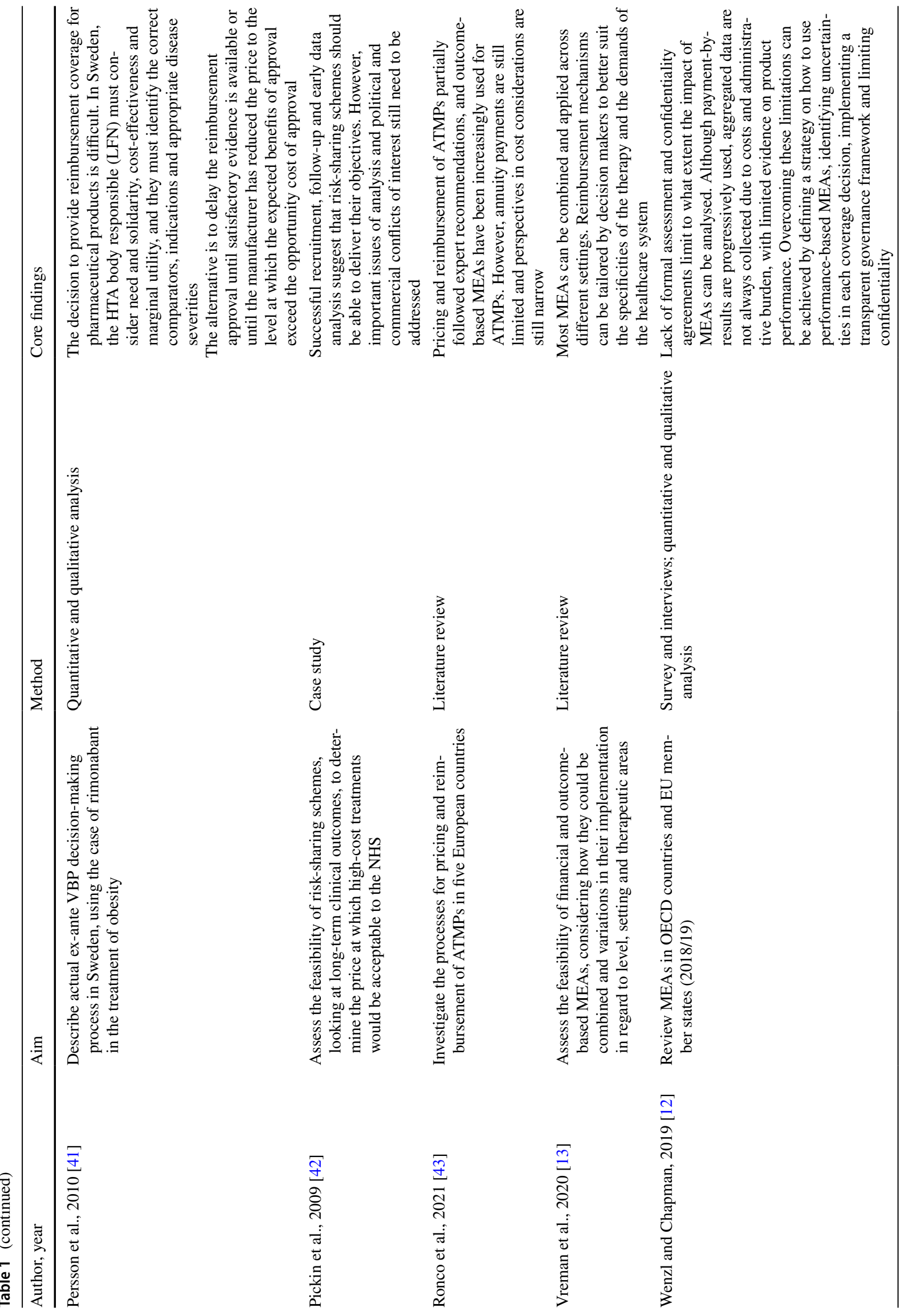




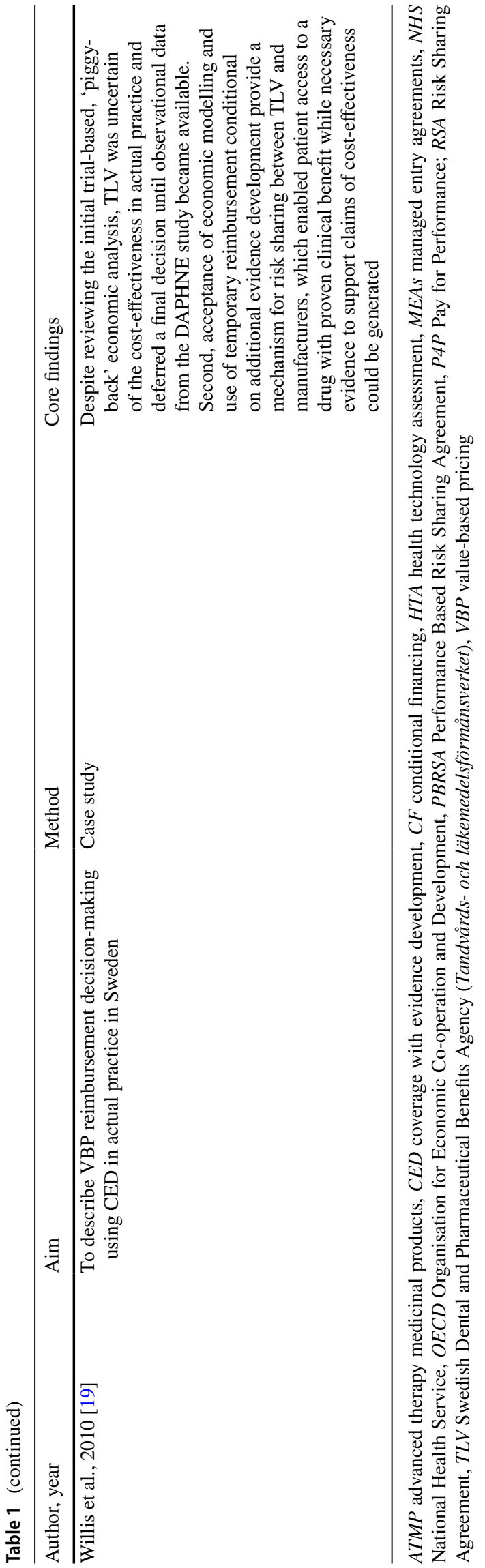

\subsubsection{Alignment}

A range of stakeholders will be involved in developing OBCs, and their assessment of value, attitude to risk, and objectives for the negotiation will vary [15]. The OBC objectives will also differ by country and healthcare system.

Establishing a shared purpose in a multi-stakeholder negotiation requires building trust, respect and an understanding of the different motivations, expectations and time frames of each party. The literature includes descriptions of a successful OBC implementation because of the 'alignment of payer and manufacturer incentives to support better outcomes' [11]. Techniques like horizon scanning can also be used to inform the contract and its conditions [14]. However, early and explicit objective setting is not standard practice in OBC negotiations [10], and this lack of a clear guidance framework may be a drawback to implementing them [20].

\subsubsection{Desirability}

When faced with considerable uncertainty about whether a product or service is cost-effective, payers have four options: adopt or partially adopt with the option to revisit the decision if more information becomes available; refuse to adopt until better information is supplied; demand or mandate a lower price; or enter into an $\mathrm{OBC}$ [10].

Whether an $\mathrm{OBC}$ represents the best reimbursement option is a significant decision for all stakeholders. It requires detailed exchange of information and data, as well as challenging questions regarding data collection, data privacy and scheme structure to be addressed upfront. Shortterm static benefits such as whether the new intervention is prescribed to the appropriate population are easier to measure than long-term, dynamic efficiency benefits that result from aligning incentives in a way that promotes high-quality research and evidence generation [7]. Typically only the former are considered explicitly, yet the latter are fundamental to evaluating the benefit of an $\mathrm{OBC}$ [10].

Assessing the desirability of different $\mathrm{OBCs}$ is made more challenging due to the limited evaluation of existing schemes in the public domain [21]. Key information such as the health outcomes measures used and the analyses performed are seldom publicly available [12], and economic modelling is uncommon [3]. Furthermore, learning from other country examples is often prevented because information about the effectiveness of the current schemes is rarely available [5].

\subsubsection{Risk}

The anatomy of an agreement comprises three basic components: the expected return; upside potential; and downside risk. The objective of all parties in an OBC is to have a fair expected return, positive upside, and limited downside. 


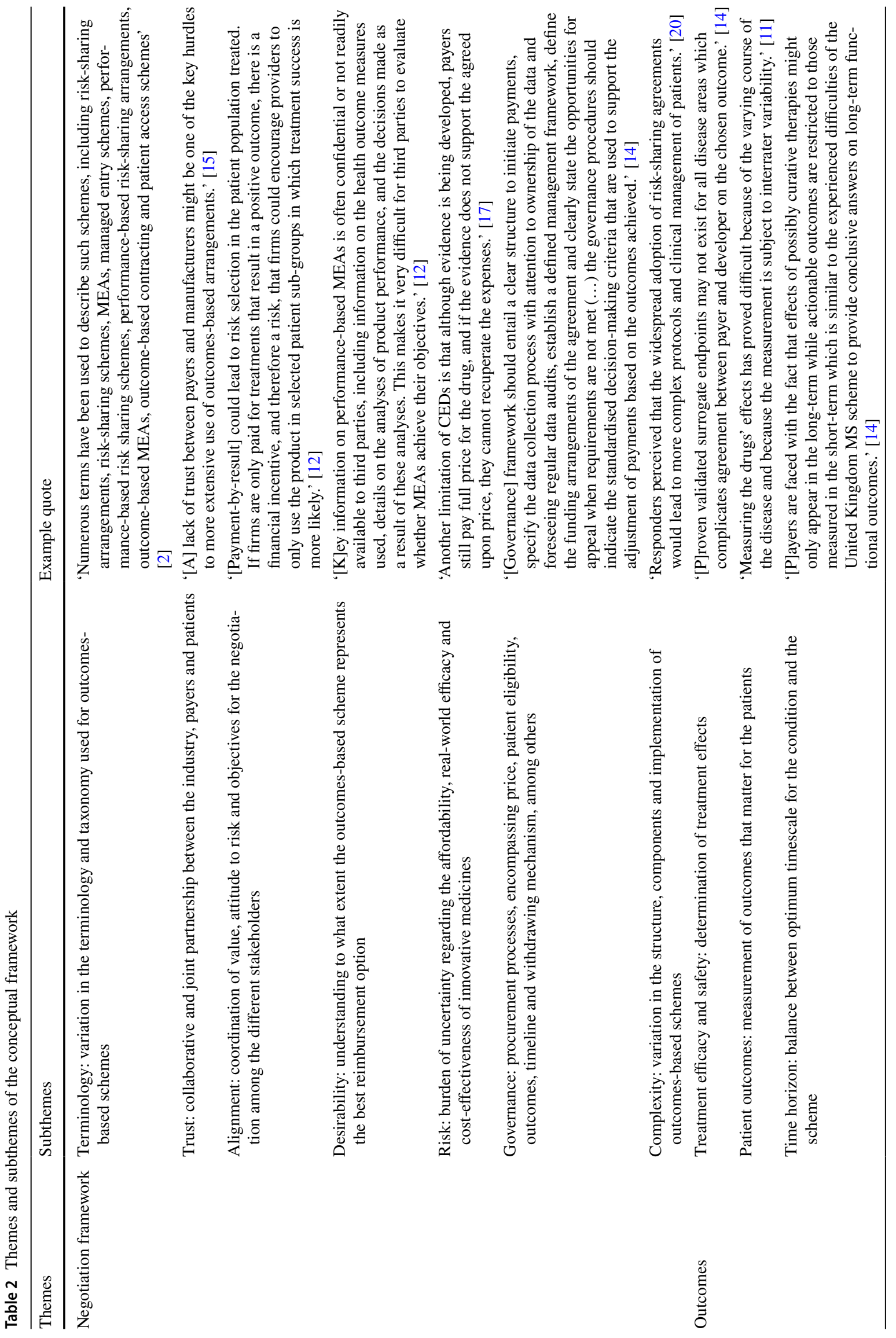




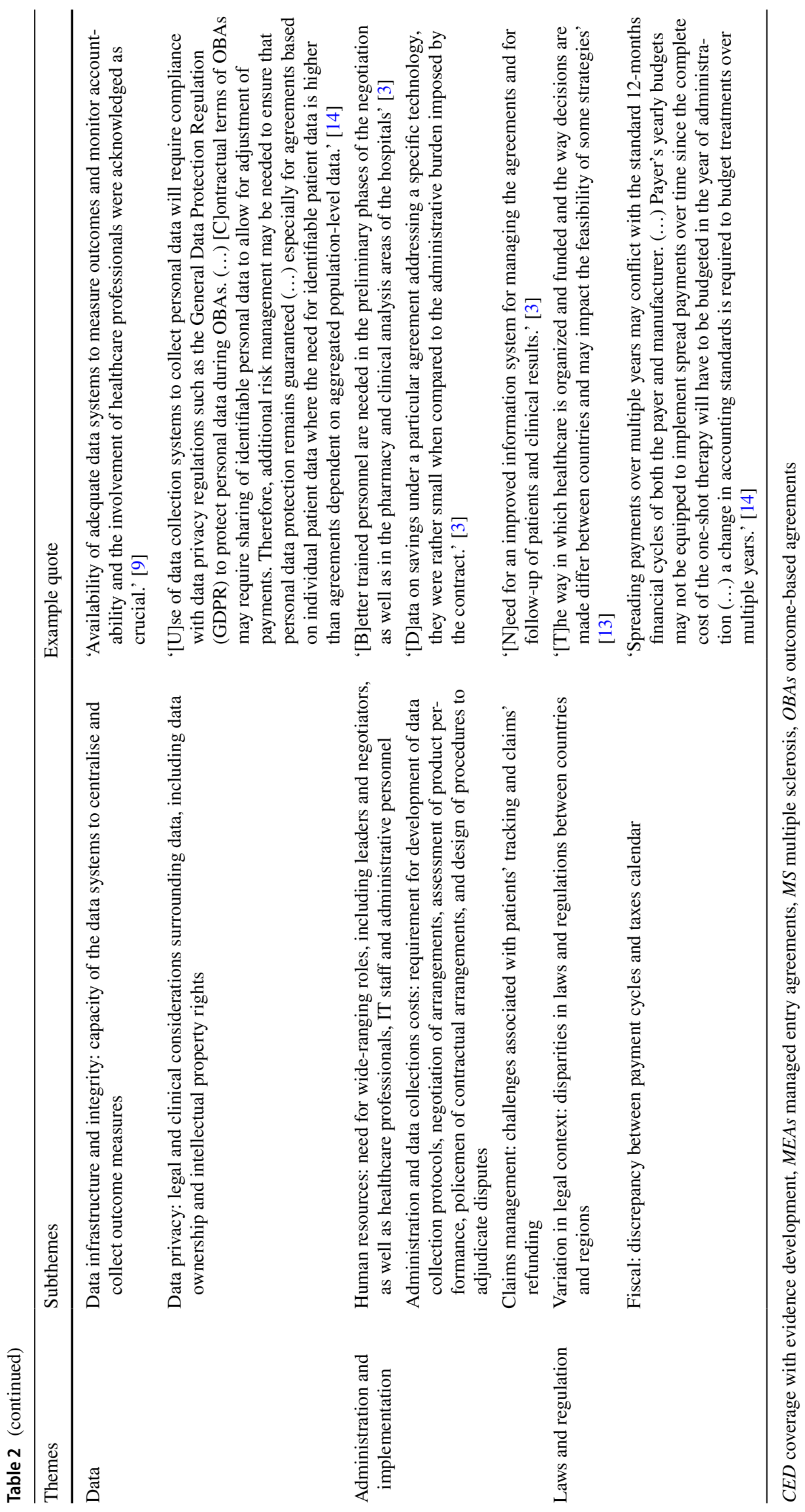


Table 3 Examples of OBCs referenced in main body text

\begin{tabular}{|c|c|c|c|c|}
\hline Programme & Partners & Year & Example of which challenge & References \\
\hline Risedronate for osteoporosis & $\begin{array}{l}\text { Warner Chilcott/Health Alli- } \\
\text { ance (USA) }\end{array}$ & 2008 & Data infrastructure & Neumann et al., 2011 [11] \\
\hline $\begin{array}{l}\text { Certolizumab pegol for rheu- } \\
\text { matoid arthritis }\end{array}$ & $\begin{array}{l}\text { UCB Pharma (Catalonia, } \\
\text { Spain) }\end{array}$ & 2017 & Complexity & $\begin{array}{l}\text { García-Collado et al., } 2021 \\
\text { [21] }\end{array}$ \\
\hline $\begin{array}{l}\text { Oxaliplatin for treatment of } \\
\text { stage III colon cancer }\end{array}$ & The Netherlands & (Not reported) & $\begin{array}{l}\text { Patient outcomes } \\
\text { Data infrastructure }\end{array}$ & Bouvy et al., 2018 [15] \\
\hline $\begin{array}{l}\text { Zoledronic acid for osteopo- } \\
\text { rosis }\end{array}$ & $\begin{array}{l}\text { Novartis/German Sickness } \\
\text { Fund }\end{array}$ & (Not reported) & Patient outcomes & Kim et al., 2020 [40] \\
\hline $\begin{array}{l}\text { Tisagenlecleucel for B-cell } \\
\text { acute lymphoblastic leukae- } \\
\text { mia and Diffuse large B-cell } \\
\text { lymphoma }\end{array}$ & $\begin{array}{l}\text { Haute Autorité de Sante } \\
\text { (France) }\end{array}$ & (Not reported) & $\begin{array}{l}\text { Human resources } \\
\text { Administration and data col- } \\
\text { lections costs }\end{array}$ & Ronco et al., 2021 [43] \\
\hline $\begin{array}{l}\text { Acetylcholinesterase inhibitor } \\
\text { for Alzheimer's disease }\end{array}$ & Italian NHS (Italy) & (Not reported) & Treatment efficacy & $\begin{array}{l}\text { Adamski et al., } 2010 \text { [16] } \\
\text { Zampirolli Dias et al., 2020 [2] }\end{array}$ \\
\hline $\begin{array}{l}\text { Beta-interferon for multiple } \\
\text { sclerosis }\end{array}$ & NHS (UK) & 2003 & $\begin{array}{l}\text { Overly long time horizons, } \\
\text { unpredictable time horizons }\end{array}$ & $\begin{array}{l}\text { Adamski et al., } 2010 \text { [16] } \\
\text { Neumann et al., } 2011 \text { [11] } \\
\text { Garrison et al., } 2013 \text { [10] }\end{array}$ \\
\hline $\begin{array}{l}\text { Continuous intraduodenal } \\
\text { infusion of levodopa/car- } \\
\text { bidopa for the treatment } \\
\text { of advanced Parkinson's } \\
\text { disease }\end{array}$ & Neopharma (Sweden) & 2005 & $\begin{array}{l}\text { Time consuming process } \\
\text { for gathering evidence and } \\
\text { negotiating reimbursement }\end{array}$ & Willis et al., 2010 [19] \\
\hline $\begin{array}{l}\text { Sitagliptin/sitagliptin } \\
\text { with metformin for diabetes }\end{array}$ & Merck/Cigna (USA) & 2009 & Effective incentive alignment & Neumann et al., 2011 [11] \\
\hline $\begin{array}{l}\text { Ranibizumab for macular } \\
\text { degeneration }\end{array}$ & Novartis/ NHS (UK) & 2008 & $\begin{array}{l}\text { Administrative burden and } \\
\text { compliance }\end{array}$ & Neumann et al., 2011 [11] \\
\hline $\begin{array}{l}\text { Nilotinib or dasatinib for } \\
\text { chronic myeloid leukaemia }\end{array}$ & (Not reported) & (Not reported) & Overly short time horizons & Garattini and Casadei, 2011 \\
\hline $\begin{array}{l}\text { Bortezomib in multiple } \\
\text { myeloma }\end{array}$ & $\begin{array}{l}\text { Johnson \& Johnson/NHS } \\
\text { (UK) }\end{array}$ & 2006 & $\begin{array}{l}\text { Administrative burden of } \\
\text { tracking patient outcomes }\end{array}$ & Neumann et al., 2011 [11] \\
\hline
\end{tabular}

NHS National Health Service, OBAs outcome-based agreements

The risk for each party associated with an $\mathrm{OBC}$ will vary for different products and populations [16]. One of the key challenges for the negotiation is balancing risk and reward for each party, taking account of their overall attitude to risk.

OBCs provide a mechanism to share the burden of uncertainty regarding the affordability, real-world efficacy and cost-effectiveness of innovative medicines between payers and the MAH [18]. However, in many cases, OBCs have been used to transfer risk from payers to the MAH, particularly in cases where the agreement on reimbursement has not been reached using the normal decision-making framework. Neumann et al. [11] raises the further question as to whether the MAH can obtain additional gains if medicines offer unexpected benefits. Conversely, for schemes like CED, it may happen that while evidence is being developed, payers still pay full price for the technology, with no possibility of recuperating those expenses if the evidence does not support the agreed upon price [17].

Agreeing which party bears the burden of proof is challenging and doing so can be complex and costly. In practice, the burden of proof sits with the beneficiary of the adjustment, which will depend on whether this is a bonus or a discount. The way in which the responsibility for establishing burden of proof is defined within an $\mathrm{OBC}$ has significant implications for the level of risk borne by each party.

\subsubsection{Governance}

It is good practice to establish clear governance structures for OBCs. Such structures should contemplate how data are collected, including who owns the data and how it will be audited; when payments are initiated; how funding is activated; and when appeals can be launched in the case of outcomes not being achieved [14]. Such schemes should be open to all eligible organisations, irrespective of size, geographical location, or product portfolio. This builds on the established procurement processes and could be in the form of 'requests for OBC' schemes amongst competing MAH in given disease areas or patient populations [16].

The cost of outcome data collection can be substantial, and ensuring the integrity and validity of the process is crucial $[11,16]$. From a legal and ethical perspective, patients 
who are having information about their health collected should be informed as to whether the payer or MAH is providing funding [16].

For an OBC to function effectively, there needs to be a clear and pre-agreed process for revising the price or the eligible patient population. Garrison et al. [10] makes a distinction between schemes that specify the way in which additional evidence will affect pricing and those with a prespecified review date at which a new price will be negotiated. If this process and the associated timelines are not clearly defined, there is a risk that access and price remain constant due to inertia, even if new evidence becomes available [11]. Neumann et al. [11] cites the example of beta-interferons in the UK which were not found to be cost-effective at the 2009 review date, yet prices had not been adjusted 2 years later.

The risk that new therapies may not be cost-effective for an individual patient or group of patients is inherent to OBCs. Prior to commencement, there needs to be an agreement in place for withdrawing the medicine, and-where applicable-transferring patients to an alternative [22]. Adamski et al. [16] concluded that clear 'exit strategies' need to be planned in advance, to respond to situations in which treatments do not achieve the specified outcomes. For patients who are benefiting, appropriate 'grandfathering' mechanisms may need to be in place. Willis et al. [19] described the situation in which the intestinal gel levodopa/ carbidopa was found not to be cost-effective, yet discontinuation would require burdensome surgery, making delisting impractical.

\subsubsection{Complexity}

OBCs are inherently more complex than standard discounts both to evaluate and to implement. This is perhaps the most commonly cited deterrent for healthcare payers $[13,15,17$, 20].

Complexity can result from variation of established standard of care between healthcare providers, making selection of a baseline or comparator more difficult. Agreeing the comparator and ensuring it has widespread use is required ahead of any OBC commencing.

An additional source of complexity is that the patients initially prescribed the medicine will not always be those most likely to benefit [16]. The clinical trial cohort of patients may not always reflect the external validity of a more heterogeneous real-world patient population. This uncertainty has significant implications for the cost-effectiveness of the medicine, and consequently the reimbursement that is linked to patient outcomes. There are some ways to mitigate this risk. Navarria et al. [18] points to the Italian example of Italian Medicines Agency (Agenzia Italiana del Farmaco) 'AIFA Notes', which limit the reimbursement of the medicine to the agreed population subgroups.

\subsection{Outcomes}

\subsubsection{Treatment Efficacy and Safety}

OBCs require stakeholders to have explicit conversations about when a therapy 'works' [11]. A major challenge lies in the specification and determination of treatment effects in non-randomised settings, where only certain types of outcome may prove suitable $[11,23]$. Changes in clinical practice over time also constrain the reliable measurement of a treatment's effectiveness [13].

Ideally, outcomes should be objective, clearly defined, reproducible and difficult to manipulate [11]. Successful OBCs have had clearly defined clinical events such as osteoporosis fractures confirmed with $\mathrm{x}$-ray or well-established biomarkers such as reduction in serum $\mathrm{M}$ protein in multiple myeloma [11].

OBCs take place in non-randomised settings and can be affected by factors beyond the control of stakeholders. Health systems, clinical pathways, treatment adherence, socioeconomic status and behavioural factors can all influence outcome collection and may not be considered during negotiations [11].

\subsubsection{Patient Outcomes}

The outcomes that matter most to patients were not explored comprehensively in the literature. Proven validated surrogate outcomes may not exist for all therapeutic areas [14]. These domains may be explored through patient-reported outcome measures (PROMs) that capture health-related quality of life, symptom burden, and/or function, and can be paired with clinical outcomes to better understand the patient experience of treatment [24]. Though Neumann et al. [11] made mention of the risk of failing to measure outcomes that matter most to patients, such as fatigue in multiple sclerosis, they cited a New York Times article that stated 'measuring improvements in the quality of life is an imprecise science at best' [25]. Both articles demonstrate a gap in understanding of the rigorous science behind patient outcomes research.

\subsubsection{Time Horizon}

The selection of treatments suitable for an OBC must consider the outcome timescale for the condition. Timeframes must be long enough to allow for a reliable clinical assessment and adequate data collection but not so long that they become difficult to enforce or execute [5, 14, 23]. For 
example, only a small proportion of chronic myeloid leukaemia patients resistant to nilotinib or dasatinib can be detected within 4 weeks [5]. Therefore, assessing haematological and cytogenic tests over a longer period-such as 3-6 months-might be a more sensible 'threshold' to distinguish non-responders from patients who are more likely to benefit from this treatment [5].

On the other hand, long timelines have other risks [17, 23]. Technological advancements can result in changed clinical practice that make the OBC obsolete. Difficulties in timelines can arise due to slow patient recruitment [5] or challenges capturing and accessing data [9].

\subsection{Data}

\subsubsection{Data Infrastructure and Integrity}

Decentralised healthcare systems often have their own data infrastructure, making it technically challenging to share patient information between systems [5, 9, 20]. Even in the UK's 'national' health system, the data infrastructure is fractured, and linkage is difficult.

One of the challenges of ensuring the reliability and validity of OBC data is that it is managed on a per patient basis, where response is based on individual trajectory and is not aggregated to inform evidence-based reimbursement decisions $[12,16,22]$. It is also challenging to guard against bias in the selection of patients. In a review of 19 OBCs, Jarosławski and Toumi [22] did not identify any process to ensure an unbiased selection of patients in Italy.

Ethical considerations are important when stakeholders are considering OBCs [16]. A lack of transparent or established procurement and monitoring processes could lead to preferential treatment, bias or gaming [16]. These concerns could be addressed through the utilisation of a trusted third party to undertake data collection or analysis within common data formats $[14,15]$.

The evaluation of proposed arrangements must also adhere to high ethical standards, including the declaration of any contacts and conflicts of interest between experts and MAH that could potentially influence evaluations [16].

\subsubsection{Data Privacy}

Legal and clinical governance considerations must be fully addressed when proposing and developing future OBCs $[2,16]$. This includes data ownership, intellectual property rights and opportunities for appeal [16]. Ensuring privacy and security of data is paramount to gain support from patients and other data owners. In Europe, MAH are bound by the General Data Protection Regulation (GDPR) and Code of Conduct on Data [26], and collection of personal data requires compliance with that regulation [14]. However, complying with data privacy regulations can add further burden to the analyses [2].

Furthermore, participation in an OBC should be clearly explained to patients and consideration should be given as to how this may complicate the principle of informed consent. These regulatory issues, and the expertise required to meet them, received limited discussion within the academic literature [12]. This may in part be due to the pace at which this area is evolving.

\subsection{Administration and Implementation}

\subsubsection{Human Resources}

For many payers, OBCs are a new paradigm, different to the tools and techniques used in previous assessment of treatments. Designing and implementing OBCs is complex, time consuming and requires strong leadership. Clopes et al. identified leadership as the most important organisational aspect of implementation of OBCs [9].

There also need to be appropriately trained professionals in place to evaluate the proposed schemes, from the preliminary stages of negotiation to the pharmacy and clinical contexts [3]. These include healthcare professionals, pharmacology, IT and economic experts [16]. Michelsen et al. [14] highlighted how low compliance with data input from healthcare professionals resulted in low-quality and insufficient data, during the implementation of CED in the Netherlands and outcome-based agreements (OBAs) in Italy. The burden of data collection for healthcare and other professionals involved, as well as patients, should be anticipated $[2,3,13]$.

To meet the expanded responsibilities of $\mathrm{OBC}$ negotiation, implementation and management, the mandates and processes of regulatory, HTA and funding organisations may need to be revised.

\subsubsection{Administration and Data Collection Costs}

OBCs generate additional costs and require additional resources, responsibility for which remains unclear. These include developing data collection protocols, negotiating arrangements, assessing product performance, policing contractual arrangements and designing procedures to adjudicate disputes. For instance, one OBC for a multiple sclerosis medicine in the UK required 120 additional nurses in 70 centres to implement the agreement [11]. Long-term funding is required alongside the technical infrastructure to capture and analyse the data. The complexity of implementing a risk-sharing agreement for enzyme replacement therapy in lysosomal storage diseases at a national level led the Spanish authorities to instead establish regional or even hospital-level agreements [27]. For certain technologies, the 
administrative burden of these schemes may offset the benefits $[2,3,13,14]$.

Variation between the administrative requirements of different schemes adds further complexity. For example, ranibizumab involved clear criteria-a dose cap at 14 injections-which resulted in a relatively low administrative burden. In contrast, the multiple sclerosis arrangement involved a longer timeframe, difficult to gauge outcomes and higher administrative costs [11].

\subsubsection{Claims Management}

Response-based schemes pose challenges for tracking patients and ensuring that refunds are claimed [3], creating an additional administrative burden [20]. A survey of oncology pharmacists in 31 UK NHS hospitals found that between 2007 and 2009, 47\% of eligible manufacturer paybacks from OBCs were not recovered by Primary Care Trusts [22]. Experience is similar in Italy, where Navarria et al. [18] suggest there is no incentive for healthcare professionals to update the registries, close the patients' files and submit a refund claim on a regular basis, possibly because the money to be refunded does not go to the prescribing cost centre, rather to the hospital general budget. Therefore, an 'incentivisation gap' exists between the stakeholder who receives the funding and the individual in charge of the reimbursement procedures $[3,18]$.

\subsection{Laws and Regulation}

\subsubsection{Variation in Legal Context}

A solid legal framework is essential to every OBC, [9] yet this can be complex to establish [11]. The laws and regulations that govern $\mathrm{OBCs}$ in each country and region are highly variable $[12,13]$. For instance, in France and the UK, price negotiations occur at a national level [10], whereas in Spain they occur at a regional level [9]. Garrison et al. [10] note that France were considering a law that would fine MAH who did not provide evidence in a timely manner to disincentivise them from holding back unfavourable results.

Navigating the diverse and evolving legal landscape is a challenge to manufacturers pursuing OBCs in multiple countries. Michelsen et al. [14] suggested how scientific advice should be sought from the European Medicines Agency (EMA) and the different HTA bodies on how to enable collaborations between the regulatory agency and multiple national payers.

\subsubsection{Fiscal}

As discussed earlier, some OBCs have long timelines, and this results in a delay in determining whether the agreed patient outcomes have been achieved. Thus, the MAH may receive payment —or payers rebates - long after the medicine is dispensed. Reimbursement may occur in a different tax year, creating fiscal and accrual challenges for all stakeholders [14], including government treasury departments [18].

\section{Discussion}

This scoping review is the first to examine the challenges of implementing OBCs across European healthcare systems, and to develop a comprehensive framework. Some of the challenges that have been highlighted are familiar; concerns around the complexity and cost of implementation, particularly in relation to data infrastructure for recording patient outcomes, have been discussed elsewhere [3, 12, 15]. This analysis of the published literature identified several lessrecognised areas for further research on challenges associated with OBCs, which are discussed below.

This review did not assess the impact of specific OBC schemes because, as has been discussed, the necessary information is generally not made available publicly. Further, the review stops short of making detailed recommendations for how to overcome the challenges discussed. As the review is limited to considering challenges within Europe, it does not include those relating to $\mathrm{OBC}$ examples in other healthcare systems, such as the United States (US).

There was little discussion in the literature of the role that patients and healthcare providers play in OBC measurement frameworks, negotiation and implementation, despite coverage of multiple issues relevant to them. Examples include incentives to participate in outcomes data collection and monitoring; the prioritisation and relevance of selected outcomes; privacy concerns surrounding data ownership, security and sharing; uncertainty around treatments being de-listed as the result of ex-post review; and the existence of subsequent treatment plans or changing treatment pathways. In our view, a critical examination of the implication of OBCs for patients and healthcare providers is vital to ensure better outcomes for all parties.

Relatedly, there is minimal discussion of outcomes that matter most to patients and how this is integral to understanding the value of a treatment [21]. The literature focuses on clinical outcomes with the apparent perception they are more objective, unbiased and quantifiable. However, quantifying the patient experience with robust methodology and analysis includes direct patient insights, disease-specific conceptual frameworks and measurement with valid, reliable and sensitive instruments used in an appropriate context [28, 29]. Evaluating these complex, and at times interdependent, variables impacting treatment outcomes creates an opportunity to enhance 
shared patient-clinician decision making [30] and system resource allocation, [31, 32] and may guide development of outcome measurement frameworks informing OBCs in the future. This has particular potential in the UK, where there is a history of using PROMs for comparisons of providers' performance [33]. Further research is critical to establish patient outcomes research methodology as a tool to transform value and access conversations.

Challenges of OBCs in the US have received coverage elsewhere, and the context for implementing OBCs differs [34-36]. This paper examines patterns in the challenges discussed in the European literature. Some of the challenges included in this study are specific to the EU, or to particular countries within the EU; others are more general. Regulatory compliance is highly contextual, with different considerations at the regional, national and international level. Clopes et al. [9] highlight the importance of Catalonian oncology policy for OBCs in that region. Complying with the GDPR and ensuring data security whilst harnessing the increasing capability to capture and analyse real-time data is a key consideration across EU health systems [26]. Research in the US context focuses less on data governance and more on other areas of legislation, such as the Medicaid Drug Rebate Program's (MDRP's) 'best price requirement' [36]. Co-ordinated pursuit of value for money via HTA is less of a dominant paradigm within the US system [37]. Although the UK has left the EU, much of the shared regulatory framework remains in place, and there is substantial commonality between health systems.

Distrust between payers and the pharmaceutical industry is a recurring theme and a characterisation of zero-sum price focused negotiations. This is one area in which the authors believe that there has been progress towards a more collaborative relationship that recognises the shared desire to achieve improved outcomes that matter most to patients. That process is based on a rigorous assessment of value throughout the whole care pathway and not simply through good negotiation skills. There is an appetite on all sides to explore greater use of $\mathrm{OBCs}$, but there does need to be greater shared understanding of the challenges faced by both industry and payers in implementing them. Trust is easily lost; without sensitivity as to where OBCs can put greater pressure on healthcare systems, it is easy to assume that the reluctance to implement them is due to other motives. This review is instrumental in highlighting the areas of potential misunderstanding so that they can be considered and addressed in advance of OBC design.

Progress has also been made towards technical OBC solutions, such as third-party platforms for facilitating data collection, analysis and payments [38]. This has the potential to build the trust needed for OBCs to function effectively and must include transparent protocols to meet data governance regulation.
There are two factors that drive the gaps that have been identified in the literature: limited transparent evaluation of existing schemes and a lag between developments within a rapidly evolving policy area and the academic literature. Future research may attempt to address these gaps by drawing on alternative sources, such as interviews, in addition to the published literature. A European register of existing schemes, with sensitive financial information removed, would enhance collective understanding.

Historically, OBCs were used as a vehicle of risk sharing, facilitating reimbursement of the MAH and reducing the risk faced by the payers. OBCs have also been used as a 'last-resort' when traditional reimbursement structures were ineffective at achieving agreement, but this is changing. For example, new medicines, including curative therapies and advanced therapy medicinal products (ATMPs) present a significant value potential, but also a cost containment challenge [39]. OBCs present a mechanism for providing reimbursement at a level proportional to the value they create, by linking the level of reimbursement, and the timing, to the outcomes achieved for patients, thus, achieving a mutually beneficial arrangement across all stakeholders. These opportunities mean they are likely to have a significant role in how the life sciences industry is reimbursed in the future.

\section{Conclusion}

Although shared information, knowledge and technical understanding are important for $\mathrm{OBC}$ implementation, they are not enough. These agreements are complex structures, which require partnership, collaboration and learning by a range of stakeholders with complementary expertise.

An OBC that worked in one place at one time will not necessarily work somewhere else or even in the same place at another time, even with the challenge appearing superficially to be the same. Acknowledging this complexity through dialogue is the first step to moving forward; parties may need to develop a fundamentally different approach to problem solving to progress from there. As European healthcare systems evolve their regulatory and reimbursement landscape, and adopt ways of contracting for innovative therapeutics that balance sustainability and innovation, appreciating the challenges highlighted by this review will be key to constructive dialogue.

Supplementary Information The online version contains supplementary material available at https://doi.org/10.1007/s40273-021-01070-1.

Acknowledgements The authors would like to thank Vasileios Kontogiannis and Corinna Bull for their contribution to this study. 


\section{Declarations}

Author Contributions SB, FGJ and AD led the development of the thematic analysis, by identifying relevant topics and subtopics. NB, JRB and HL contributed with comments to the thematic analysis. SB, FGJ, $\mathrm{DGB}$ and $\mathrm{AD}$ were involved in the literature review and data extraction. All authors contributed to the writing of this article and reviewed and approved the manuscript.

Funding This study was partially funded by Pfizer Limited.

Conflict of interest NB and JRB are employees of Pfizer Limited. HL is employed by Swansea University, which has received funding from Pfizer Limited. SB, FGJ, DGB and AD are employees of Symmetron Limited, who received funding from Pfizer Limited to complete this work.

Ethics approval Not applicable.

Consent to participate Not applicable.

Consent for publication Not applicable.

Availability of data and material Data available on request.

Code availability Not applicable.

Open Access This article is licensed under a Creative Commons Attribution-NonCommercial 4.0 International License, which permits any non-commercial use, sharing, adaptation, distribution and reproduction in any medium or format, as long as you give appropriate credit to the original author(s) and the source, provide a link to the Creative Commons licence, and indicate if changes were made. The images or other third party material in this article are included in the article's Creative Commons licence, unless indicated otherwise in a credit line to the material. If material is not included in the article's Creative Commons licence and your intended use is not permitted by statutory regulation or exceeds the permitted use, you will need to obtain permission directly from the copyright holder. To view a copy of this licence, visit http://creativecommons.org/licenses/by-nc/4.0/.

\section{References}

1. Catchpole P, Barrett V. Keeping pace with pharmaceutical innovation: the importance of the NICE methods review. Pharmacoeconomics. 2020;38(9):901-3.

2. Zampirolli Dias $\mathrm{C}$, et al. Integrative review of managed entry agreements: chances and limitations. Pharmacoeconomics. 2020;38(11):1165-85

3. Antonanzas F, et al. The use of risk-sharing contracts in healthcare: theoretical and empirical assessments. Pharmacoeconomics. 2019;37(12):1469-83.

4. Darbà J, Ascanio M. The current performance-linked and risk sharing agreement scene in the Spanish region of Catalonia. Expert Rev Pharmacoecon Outcomes Res. 2019;19(6):743-8.

5. Garattini L, Casadei G. Risk sharing agreements: what lessons from Italy? Int J Technol Assess Health Care. 2011;27(2):169-72.

6. Carlson JJ, Chen S, Garrison LP. Performance-based risk-sharing arrangements: an updated international review. Pharmacoeconomics. 2017;10(35):1063-72.
7. Arksey H, O'Malley L. Scoping studies: towards a methodological framework. Int J Soc Res Methodol. 2005;8(1):19-32.

8. Cole A, et al. Making Outcome-Based Payment a Reality in the NHS. 2019. https://doi.org/10.1007/s40271-020-00430-x.

9. Clopes A, et al. Financial consequences of a payment-by-results scheme in Catalonia: gefitinib in advanced EGFR-mutation positive non-small-cell lung cancer. J Med Econ. 2017;20(1):1-7.

10. Garrison LP Jr, et al. Performance-based risk-sharing arrangements; good practices for design, implementation, and evaluation: report of the ISPOR good practices for performancebased risk-sharing arrangements task force. Value Health. 2013;16(5):703-19.

11. Neumann PJ, et al. Risk-sharing arrangements that link payment for drugs to health outcomes are proving hard to implement. Health Aff. 2011;30(12):2329-37.

12. Wenzl M, Chapman S. Performance-based managed entry agreements for new medicines in OECD countries and EU member states: how they work and possible improvements going forward, in Health Working Papers OECD. 2019.

13. Vreman RA, et al. Application of managed entry agreements for innovative therapies in different settings and combinations: a feasibility analysis. Int J Environ Res Public Health. 2020;17(22):8309.

14. Michelsen S, et al. Barriers and opportunities for implementation of outcome-based spread payments for high-cost, one-shot curative therapies. Front Pharmacol. 1914;2020(11):5.

15. Bouvy JC, Sapede C, Garner S. Managed entry agreements for pharmaceuticals in the context of adaptive pathways in Europe. Front Pharmacol. 2018;9:280.

16. Adamski J, et al. Risk sharing arrangements for pharmaceuticals: potential considerations and recommendations for European payers. BMC Health Serv Res. 2010;10:153-153.

17. Dabbous $\mathbf{M}$, et al. Managed entry agreements: policy analysis from the European perspective. Value Health. 2020;23(4):425-33.

18. Navarria A, et al. Do the current performance-based schemes in Italy really work? "Success fee": a novel measure for cost-containment of drug expenditure. Value Health. 2015;18(1):131-6.

19. Willis M, et al. Reducing uncertainty in value-based pricing using evidence development agreements. Appl Health Econ Health Policy. 2010;8(6):377-86.

20. Lorente R, Antonanzas F, Rodriguez-Ibeas R. Implementation of risk-sharing contracts as perceived by Spanish hospital pharmacists. Heal Econ Rev. 2019;9(1):25.

21. García-Collado CG, et al. Impact of a risk-sharing agreement in rheumatoid arthritis in Spain. Health Policy. 2021;125(3):335-40.

22. Jarosławski S, Toumi M. Market access agreements for pharmaceuticals in Europe: diversity of approaches and underlying concepts. BMC Health Serv Res. 2011;11(1):259.

23. Makady A, et al. Implementing managed entry agreements in practice: the Dutch reality check. Health Policy. 2019;123(3):267-74.

24. US Food \& Drug Administration. Patient-Reported Outcome Measures: Use in Medical Product Development to Support Labeling Claims. 2009. https://www.fda.gov/regulatory-information/ search-fda-guidance-documents/patient-reported-outcome-measu res-use-medical-product-development-support-labeling-claims. Accessed 2020

25. Pollack A. Pricing pills by the results. New York Times. 2007. https://www.nytimes.com/2007/07/14/business/14drugprice.html. Accessed 14 Jul 2007.

26. Department of Health \& Social Care. Code of conduct for datadriven health and care technology. 2019. https://www.gov.uk/ government/publications/code-of-conduct-for-data-driven-healthand-care-technology/initial-code-of-conduct-for-data-drivenhealth-and-care-technology. Accessed 2020. 
27. Edo-Solsona MD, Vitoria-Minana I, Poveda-Andres JL. Implementation and results of a risk-sharing scheme for enzyme replacement therapy in lysosomal storage diseases. Farm Hosp. 2020;44(1):10-5.

28. Deshpande PR, et al. Patient-reported outcomes: a new era in clinical research. Perspect Clin Res. 2011;2(4):137-44.

29. The European Patients' Academy on Therapeutic Innovation (EUPATI). Patient-reported outcomes (PROs) assessment. 2020. https://toolbox.eupati.eu/resources/patient-reported-outcomespros-assessment/. Accessed 2020.

30. National Insitute for Health and Care Excellence (NICE). Shared decision making. 2021. https://www.nice.org.uk/about/what-wedo/our-programmes/nice-guidance/nice-guidelines/shared-decis ion-making. Accessed 2021.

31. Basch E, et al. Recommendations for incorporating patientreported outcomes into clinical comparative effectiveness research in adult oncology. J Clin Oncol. 2012;34(30):4249-55.

32. Guindo LA, et al. From efficacy to equity: Literature review of decision criteria for resource allocation and healthcare decisionmaking. Cost Effective Resourc Alloc. 2012;10(1):9.

33. Black N. Patient reported outcome measures could help transform healthcare. Br Med J. 2013;346:167.

34. Brown JD, et al. Payer and pharmaceutical manufacturer considerations for outcomes-based agreements in the United States. Value Health. 2018;21(1):33-40.

35. Seeley E, Kesselheim AS. Outcomes-based pharmaceutical contracts: an answer to high US Drug Spending? 2017. https:// www.commonwealthfund.org/publications/issue-briefs/2017/sep/ outcomes-based-pharmaceutical-contracts-answer-high-us-drug. Accessed 2021.
36. Mytelka D, et al. Managing uncertainty in drug value: outcomesbased contracting supports value-based pricing. Health Affairs Blog. 2020. https://www.healthaffairs.org/do/10.1377/hblog20200 128.542919/full/. Accessed 30 Jan 2020.

37. Mulligan K, et al. Health technology assessment for the US Healthcare system. 2020. https://healthpolicy.usc.edu/wp-conte nt/uploads/2020/02/Health-Technology-Assessment-for-the-U. S.-Healthcare-System_White-Paper.pdf.

38. Kent S, et al. Common problems, common data model solutions: evidence generation for health technology assessment. Pharmacoeconomics. 2021;39:275-85.

39. Heppolette W, Rouse J. Pharmaceutical industry memorandum of understanding. 2017. https://www.gmhsc.org.uk/wp-content/uploa ds/2018/04/05-Pharma-Industry-MoU-Cover-Sheet-FINAL.pdf.

40. Kim AE, et al. Performance-Based risk-sharing arrangements (PBRSA): is it a solution to increase bang for the buck for pharmaceutical reimbursement strategy for our nation and around the world? Clin Drug Investig. 2020;40(12):1107-13.

41. Persson U, Willis M, Odegaard K. A case study of ex ante, valuebased price and reimbursement decision-making: TLV and rimonabant in Sweden. Eur J Health Econ. 2010;11(2):195-203.

42. Pickin $\mathrm{M}$, et al. The multiple sclerosis risk sharing scheme monitoring study-early results and lessons for the future. BMC Neurol. 2009;9:1-1.

43. Ronco V, et al. Price and reimbursement of advanced therapeutic medicinal products in Europe: are assessment and appraisal diverging from expert recommendations? J Pharmaceut Policy Pract. 2021;14(1):30. 